Archives de sciences sociales des religions

136 | octobre - décembre 2006

Les Archives... cinquante ans après

\title{
In memoriam Yves Lambert (1946-2006)
}

Jean-Paul Willaime

\section{(2) OpenEdition}

Journals

Édition électronique

URL : http://journals.openedition.org/assr/3818

DOI : $10.4000 /$ assr.3818

ISSN : $1777-5825$

Éditeur

Éditions de l'EHESS

Édition imprimée

Date de publication : 1 décembre 2006

Pagination : 71-73

ISBN : 2-7132-2124-2

ISSN : 0335-5985

Référence électronique

Jean-Paul Willaime, "In memoriam Yves Lambert (1946-2006)», Archives de sciences sociales des religions [En ligne], 136 | octobre - décembre 2006, mis en ligne le 06 février 2007, consulté le 01 mai 2019. URL : http://journals.openedition.org/assr/3818; DOI : 10.4000/assr.3818 


\section{Jean-Paul Willaime}

\section{In memoriam Yves Lambert (1946-2006)}

Notre ami Yves Lambert, bien connu des sociologues des religions en France et au-delà, est décédé lundi 28 août 2006 à l'âge de 60 ans après un combat de douze ans contre le cancer. Membre du comité de rédaction de notre revue, il y publia nombre d'études après son premier article de 1986 «Un paradigme inspiré de Weber. Pour contribuer à renouveler le débat sur la sécularisation » (61, 1986, 153-165) jusqu'à sa note critique de 2003 : "Histoires d'héritage... " à propos d'ouvrages relatifs au catholicisme français $(124,2003,39-48)$ en passant, notamment, par le numéro 109 (2000) sur les « Formes religieuses caractéristiques de l'ultramodernité : France, Pays-Bas, États-Unis, Japon. Analyses globales », numéro qu'il avait dirigé et auquel il apporta une contribution substantielle: "Religion ; modernité, ultramodernité : une analyse en terme de "tournant axial” " (87-116).

Né le 16 mars 1946 à Marsais (Charentes-Maritimes), Yves Lambert suivit une formation d'ingénieur agronome et de sociologie (doctorat de $3^{\text {e }}$ cycle de l'EHESS en 1982 sous la direction de Pierre Bourdieu). Il débuta sa carrière en sociologie rurale à l'Institut national de la recherche agronomique (INRA) où il fut successivement assistant (1971), chargé de recherches (1976), puis directeur de recherches (1985). Se tournant très vite vers la sociologie des religions, il fut mis à disposition du CNRS dès 1993 et rejoignit, lors de sa création en 1995, le Groupe de Sociologie des Religions et de la Laïcité. C'est au sein de cette Unité mixte de recherches EPHE-CNRS qui s'appelle aujourd'hui Groupe Sociétés, Religions, Laïcités qu'il s'affirma comme un des sociologues français des religions marquant de sa génération.

Dans son ouvrage Dieu change en Bretagne. La religion à Limerzel de 1900 à nos jours (Paris, Cerf, 1985), Yves Lambert pratiqua une ethnosociologie du catholicisme ordinaire associant les méthodes et les disciplines, le quantitatif et le qualitatif. Dans cette étude localisée, devenue un classique en sciences sociales des religions, il décrivit et analysa avec minutie, dans ce village de la Bretagne rurale en état de chrétienté jusque la fin des années cinquante, la fin de la civilisation paroissiale. Tout en notant la baisse spectaculaire des pratiques traditionnelles, Yves Lambert s'attachait à montrer en quoi les paroissiens, loin d'être les 
sujets passifs de la sécularisation moderne, en étaient aussi d'actifs agents qui critiquaient et réélaboraient en même temps la religion dans un sens plus mondain. Dans la recension que, l'année même de sa parution, Danièle Hervieu-Léger en fit dans le numéro 60-2 des Archives, elle salua l'ouvrage en notant qu'en mettant remarquablement à jour " les limites d'une approche "plate" de la sécularisation comme perte de la religion ", Yves Lambert appelait « la réflexion sur les productions religieuses de la modernité ", une réflexion à laquelle il apportera lui-même une contribution originale avec son hypothèse du tournant axial et ses analyses sur l'évolution religieuse de l'Europe ( $\mathrm{A}$ Turning Point in Religious Evolution in Europe ", Journal of Contemporary Religion, 19-1, 2004, 29-45). Vingt ans après, autour des années 2000, Yves Lambert souhaitait réitérer une enquête approfondie à Limerzel : la maladie et la mort ne lui en auront pas laissé le temps.

C'est à l'étude quantitative des évolutions des croyances et pratiques religieuses - notamment des jeunes - qu'Yves Lambert se consacra tout particulièrement par la suite. Il fut, en sociologie des religions, le spécialiste français incontesté des enquêtes européennes sur les valeurs qui, périodiquement, mesurent et comparent, d'un pays à l'autre, ces évolutions. Cela nous valut des contributions rigoureuses et abondamment citées aussi bien dans les revues spécialisées (Revue Française de Sociologie, Social Compass, Journal of Contemporary Religion, Sociology of Religion...) que dans des ouvrages collectifs (Les valeurs des Français, sous la dir. de Pierre Bréchon, Armand Colin, 2000-2003), mais aussi de nombreux articles et interviews dans des revues grand public (Futuribles, Sciences Humaines) et dans la presse. Dans ces analyses de données quantitatives, Yves Lambert s'employa tout particulièrement à bien distinguer les effets d'âges des effets de générations en suivant l'évolution des attitudes religieuses de différentes cohortes, ce qui lui permit d'apporter la preuve d'une évolution significative des générations d'après-guerre dans leur rapport au religieux. Dans ses analyses de l'enquête européenne de 1999, il attira l'attention des chercheurs sur le fait que la tendance au déclin du religieux dans les sociétés européennes apparaissait désormais contrebalancée par deux autres tendances observables particulièrement chez les jeunes : un "ressaisissement chrétien interne » et un "croire sans appartenance » selon la célèbre formule de Grace Davie ( $c f$. "Des changements dans l'évolution religieuse de l'Europe et de la Russie », Revue Française de Sociologie, 45-2, 2004, 307-338). À travers ce type de travaux, Yves Lambert a participé, en tant que sociologue des religions, à des revues et ouvrages de sociologie générale, milieu disciplinaire dans lequel il était parfaitement intégré.

Jusque sur son lit d'hôpital et avec le soutien de son épouse, il continuait à travailler à un ambitieux projet qui lui tenait particulièrement à cœur : une sociologie comparée des religions allant du chamanisme aux religions monothéistes en passant par les religions orales agraires et les religions polythéistes antiques. 
Un pari risqué, mais qui intéressa aussi bien les sociologues des valeurs que les anthropologues et dont certaines parties devraient être publiées prochainement. Membre de plusieurs sociétés scientifiques: l'Association française de sciences sociales des religions (qu'il présida de 1992 à 1998), la Société internationale de sociologie des religions, l'Association for the Sociology of Religion, l'Association pour la recherche sur les valeurs (dont il fut le co-fondateur), Yves Lambert apportait, depuis 1993, une contribution active au comité de rédaction des Archives de Sciences Sociales des Religions. Il participait volontiers à la formation des étudiants et des chercheurs, tant à Rennes qu'à Paris, et apportait avec générosité les éclairages de ses analyses à des publics très divers. 